\title{
Terapia celular em tratamento de doenças do sistema nervoso
}

\section{Cell therapy as treatment for neural system diseases}

Liana Costa Pereira' Paulo Roberto Queiroz ${ }^{2}$

\footnotetext{
* Recebido em: 17/02/2012 Aprovado em: 17/12/2012

1 Graduanda do curso de Biomedicina, Centro Universitário de Brasília - UniCEUB, Brasília/ DF, nanacp_89@hotmail.com

2 Doutor em Biologia Molecular, professor do curso de Biomedicina, Centro Universitário de Brasília - UniCEUB, Brasília/DF, pqsilva@uol. com.br
}

\section{Resumo}

As células-tronco se apresentam no meio científico como promessas da medicina regenerativa, e visam tanto o estabelecimento da melhora ou até mesmo a cura de várias doenças ditas como degenerativas. Entre elas, estão as doenças que acometem o Sistema Nervoso, sendo que os vários estudos publicados, e ainda em andamento, mostram resultados muito promissores. O uso de células-tronco embrionárias e, principalmente de células-tronco adultas, abre várias possibilidades de tratamento, já que essas células se mostraram diferenciadas tanto por técnicas de indução quanto de transdiferenciação, bem como capazes de liberar fatores neurotróficos conhecidos por ajudar na neurogênese e proteção das células neurais. Este trabalho de revisão bibliográfica teve como objetivo descrever o potencial terapêutico dessas células em doenças relacionadas com o Sistema Nervoso.

Palavras-chave: Células-tronco. Células-tronco neurais. Doenças neurodegenerativas.

\begin{abstract}
The stem cells present themselves in the science community as promises of the regenerative medicine, which targets either improvement or even cure of many diseases described as degenerative. These include diseases that affect the Nervous System, which have been studied showing very promising results. The use of embryonic stem cells and, mainly, adult stem cells, opened multiple treatment options, as these cells already showed to be capable of releasing neurotrophic factors known to be able to help in neurogenesis and to protect neural cells, once differentiated by induction techniques and by transdifferentiation. This paper aim to review the literature on the therapeutic potential of these cells in diseases related to the Nervous System.
\end{abstract}

Keywords: Stem-cells. Neural stem-cells. Neurodegenerative diseases. 


\section{Introdução}

Células-tronco são, por definição, células indiferenciadas ou não especializadas com grande capacidade de proliferação, não só de originar outras células-tronco, como também, quando colocadas em determinadas condições fisiológicas, de originar diferentes linhagens especializadas (SOUZA et al., 2003a; ELIAS, 2005a; ABREU et al., 2008a; YARAK; OKAMOTO, 2010a).

A abordagem terapêutica que se utiliza de célulastronco é chamada de terapia celular; terapia esta bastante promissora e que permanece em destaque mundialmente, pois propõe o estabelecimento de melhora ou manutenção da qualidade de vida de indivíduos que sofrem de patologias que não possuem cura descrita e são extremamente debilitantes, ditas como degenerativas (LIMA et al., 2009).

Utilizadas há várias décadas em transplantes de medula óssea, as células-tronco se apresentam na ciência como fontes de tecidos para a regeneração daqueles que apresentam alguma anormalidade no organismo. Representam, nesse contexto, uma nova categoria da medicina, a medicina regenerativa (LIMA et al., 2009; CABELEIRA et al., 2010).

Por servirem como restauradoras da função de células e tecidos danificados, sem a necessidade de utilização de fármacos imunossupressores e, no caso das células-tronco adultas, sem a preocupação com a compatibilidade entre doador e receptor, as células-tronco são a alternativa em que mais a comunidade científica tem colocado suas expectativas. Ainda sim, a utilização dessas células apresenta desvantagens, pois os mesmos mecanismos usados para sua proliferação são aqueles que também possuem vínculo com o desencadeamento de processo carcinogênico quando falham em regular a diferenciação das células-tronco, falhas que ocorrem, geralmente, por acúmulos de mutações oncogênicas (SOUZA et al., 2003; PEREIRA, 2008).

É com esse fato em mente que os cientistas têm concentrado cada vez mais suas atenções para a realização de pesquisas, que procuram tanto respostas sobre os mecanismos de crescimento e diferenciação das células-tronco, quanto como utilizar isso em favor dos pacientes (SOUZA; ELIAS, 2005).

Dentre as várias doenças em estudo, estão as doenças que acometem o Sistema Nervoso Central (SNC), que são as de maior prevalência, mortalidade e morbidade em países desenvolvidos e em desenvolvimento (OTERO et al., 2009).

Dessa forma, há vários estudos em andamento, para se definir qual o tipo de célula que se adapta melhor para cada enfermidade, qual a melhor via de administração e também, a eficácia de tais tratamentos propostos. Sendo ainda grande o interesse da utilização de transplante de células-tronco para a regeneração das células cerebrais (PAULA et al., 2005). A meta desses estudos é a cura ou, pelo menos, a melhora de indivíduos debilitados por doenças graves, como a doença de Alzheimer ou a doença de Huntington, entre outras doenças tão graves quanto, mas menos frequentes (SOUZA; ELIAS, 2005).

O objetivo deste trabalho foi descrever por meio de uma revisão bibliográfica o potencial de uso das células-tronco em tratamentos de doenças relacionadas ao sistema nervoso.

\section{Classificação das células-tronco}

As células-tronco podem ser classificadas quanto à sua natureza e potencialidade de diferenciação, podendo ser embrionárias ou adultas. As embrionárias são divididas em: totipotentes, obtidas do interior da massa celular de embriões em estado de blastocisto, capazes de gerar todos os tipos celulares embrionários e extraembrionários, sendo transitórias no organismo, pois desaparecem poucos dias após a concepção; e pluripotentes, que têm a capacidade de originar células derivadas das três camadas germinativas: mesoderma, endoderma e ectoderma; além de apresentarem alta capacidade de proliferação, terem morfologia típica, expressarem marcadores específicos (por exemplo, SSEA-3, SSEA-4, OCT-4, SOX-2, NANOG, KLF4) e serem capazes de formar teratomas (ABREU et al., 2008; CARRION et al., 2009; YARAK; OKAMOTO, 2010).

Em função dessa alta capacidade de autorrenovação das células-tronco embrionárias, elas são vistas como fontes exemplares para a substituição de tecidos lesionados ou danificados por alguma doença quando usadas nas terapias celulares (OTERO et al., 2009).

Já as células-tronco adultas são divididas em: multipotentes, capazes de gerar tipos celulares que compõem tecidos e órgãos específicos de seu local de origem; oli- 
gopotentes, que ainda se diferenciam em algumas células provenientes de um mesmo folheto embrionário; e onipotentes, que vão se diferenciar em um único tipo celular de um folheto embrionário (NISHIKAWA et al. 2009).

Por serem responsáveis pela homeostase dos tecidos, as células-tronco adultas estão presentes na maioria deles como: sangue, pele, cérebro e tecido adiposo (CARRION et al., 2009). Essas células trabalham na reposição das que foram danificadas, perdidas durante o processo de maturação e também, daquelas que já envelheceram (YARAK; OKAMOTO, 2010).

Acreditava-se que essa categoria de células teria opções mais restritas quanto a sua plasticidade (capacidade de modificar suas características). Mas, recentemente, com o objetivo de se melhorar tal qualidade das células-tronco adultas, os cientistas conseguiram potencializar ainda mais o processo de diferenciação delas com técnicas que envolvem: a transferência do núcleo de uma célula somática para outra e também, por reprogramação das células adultas ao estágio embrionário, com a introdução de genes já conhecidos por determinarem a pluripotência de tais células, processo este ao qual foi dado o nome de transdiferenciação (CARRION et al., 2009, NISHIKAWA et al., 2009).

Atualmente, em um grande número de estudos clínicos em andamento, as células-tronco adultas têm sido usadas, não só por conta de sua facilidade de obtenção, mas também pela eficácia e segurança já comprovadas em ensaios pré-clínicos (SCHUSTER et al., 2008).

\section{0 tecido nervoso}

O Sistema Nervoso é um dos sistemas mais complexos do corpo humano, tanto pela sua estrutura quanto pelas funções que exerce. É dividido em duas grandes áreas: o Sistema Nervoso Central, responsável em grande parte pelo armazenamento da memória; e o Sistema Nervoso Periférico, responsável por receber os estímulos sensoriais de todo o corpo e direcionar para as partes superiores do tecido e por retransmitir os sinais no sentido contrário (GUYTON; HALL, 2002).

É formado por três conjuntos diferentes de células, sendo os neurônios e as células da glia que se originam do tecido ectodérmico, e células da micróglia, originadas do mesoderma. Em relação aos neurônios, já foram descritos mais de 32 tipos distintos que possuem funções e ca- racterísticas morfológicas diferentes entre si (ALVAREZBUYLLA; LIM, 2004). Entre eles, estão os neurônios motores da medula espinhal e os neurônios principais dos gânglios simpáticos (KIERNAN, 2003).

Todo o processo de armazenamento e estimulação sensorial realizado pelos neurônios é possível, graças à transmissão de impulsos nervosos pelas sinapses entre os bilhões dessas células que constituem o sistema nervoso, como uma rede altamente integrada. As sinapses podem ser de dois tipos principais: químicas, que envolvem a liberação de substâncias conhecidas como neurotransmissores (por exemplo: dopamina e serotonina); e elétricas, que consistem em condução da eletricidade por canais iônicos abertos direto de líquidos para a célula mais próxima (GUYTON; HALL, 2002).

Já as células da glia compreendem os astrócitos, oligodendrócitos e células epidimárias. A primeira categoria de células serve como preenchimento nos espaços entre os neurônios, além de possibilitar suporte físico aos outros elementos nervosos, podem absorver também alguns neurotransmissores, ajudando dessa forma no encerramento do processo pós-sináptico. A segunda categoria, os oligodendrócitos, exerce a função de síntese e manutenção da bainha de mielina dos axônios SNC, sendo que, nos nervos periféricos, isso fica a cargo das células de Schwann. As terceiras, as células epidimárias, fazem parte do epitélio, que reveste todo o sistema ventricular e são divididas ainda em três tipos: os epidimócitos, os tanícitos e a células epiteliais coroideias (KIERNAN, 2003).

Mesmo com todos esses conjuntos de células, fazse necessária a proteção do tecido contra microrganismos, função esta exercida, ainda que não muito evidente, pelas células da micróglia, que fazem o papel de macrófagos no sistema nervoso, podendo adquirir propriedades fagocíticas (KIERNAN, 2003).

O sistema nervoso central é organizado em regiões importantes como, medula espinhal, mesencéfalo, ponte, cerebelo, diencéfalo (do qual faz parte o hipotálamo) e telencéfalo. Cada uma dessas regiões apresenta um papel específico tanto no controle das vias sensitivas quanto em processos mais complexos como acumular informações a nível intelectual (KIERNAN, 2003).

Por essa razão, a atenção e cuidado com os estudos que envolvem terapias para doenças que acometem o sistema nervoso central são tão importantes, visto que 
se trata de um tecido incrivelmente interessante e ainda pouco conhecido.

\subsection{0 potencial de regeneração do sistema nervoso}

Nas décadas de 1960 e 1970, Altman e Kaplan relataram a presença de células no encéfalo adulto que originariam novos neurônios, e, em meados da década de 1990, cientistas isolaram células-tronco neurais multipotentes do encéfalo de ratos adultos (SCHWINDT et al., 2005). Mas, ainda com esses dados, os cientistas não entendiam por completo a capacidade regenerativa do sistema nervoso.

Hoje, sabe-se que o Sistema Nervoso Central possui uma pequena capacidade de autorreparação, por conta da presença de células-tronco adultas neurais ou células progenitoras neurais em duas regiões do cérebro humano: na zona subventricular do ventrículo lateral e na zona subgranular do giro denteado no hipocampo (BARTLEY et al., 2005; CARRION et al., 2009; PEVNY; NICOLIS, 2009).

As células-tronco neurais presentes nesses locais apresentam-se em pequenas quantidades e se dividem devagar, sendo que podem se diferenciar em neurônios e células da glia. Algumas evidências apontam que essas células-tronco neurais são remanescentes das células-tronco encontradas nos estágios embrionários, pois mostram várias características e marcadores em comum (ALVAREZ-BUYLLA; LIM, 2004).

O mecanismo de plasticidade do SNC, em que ele é capaz de modificar algumas respostas funcionais e, até mesmo, suas propriedades morfológicas (OLIVEIRA; SALINA; ANNUNCIATO, 2001), é chamado de neurogênese. Ocorre durante toda a vida e está relacionado com atividades que proporcionam prazer ao indivíduo, bem como com exercícios físicos regulares; ainda assim, mesmo que o SNC possua células-tronco neurais, ele não consegue recrutá-las eficazmente (SCHWINDT et al., 2005; CARRION et al., 2009).

Essa plasticidade vai se apresentar em três etapas: o desenvolvimento, em que cada neurônio se comunica com outros por meio de marcadores moleculares e sinais quimiotáticos, sendo auxiliados por fatores neurotróficos; a aprendizagem, em que haverá mudanças estruturais e funcionais nas conexões das células, como crescimento de novas terminações sinápticas e estreitamento das sinapses já existentes, além da introdução de mais neurotransmissores; e após lesões, em que ocorre um processo de excitotoxicidade por conta da liberação do neurotransmissor glutamato na fenda sináptica, alterando, dessa forma, o equilíbrio do íon cálcio levando os neurônios à morte (OLIVEIRA; SALINA; ANNUNCIATO, 2001).

Quanto aos fatores neurotróficos (Tabela 1) liberados no SNC, são descritos como proteínas com capacidades regenerativas, auxiliando na formação de novos botões terminais e na estimulação do crescimento de axônios, permitindo a sobrevivência neuronal. Acreditase que são produzidos por outros neurônios para agir em determinadas classes de neurônios (OLIVEIRA; SALINA; ANNUNCIATO, 2001; GUZEN et al., 2008).

Entre os fatores neurotróficos já descritos, estão a família do fator de crescimento fibroblástico básico (bFGF - basic fibroblast growth factor), que envolve o FGF-2 sendo este o mais abundante nas células neurais; fator de crescimento do nervo (NGF - nerve growth factor); fator neurotrófico derivado do cérebro (BDNF brain derived neurotrophic factor); fator neurotrófico derivado da glia (GDNF - glial derived neurotrophic factor); fator de crescimento fibroblástico ácido (aFGF - acidic fibroblast growth factor); fator de crescimento epidérmico (EGF - epidermal growth factor); neurotrofina-3; neurotrofina-4; fator neurotrófico ciliar (CTNF - ciliary neurotrophic factor) além de outros (DE OLIVEIRA; SALINA; ANNUNCIATO, 2001; SEBBEN et al., 2011).

Com o avanço dos estudos biotecnológicos, já é possível a produção desses e de outros fatores neurotróficos em laboratório, por serem essenciais tanto na recuperação funcional dos neurônios diante de uma lesão, quanto para a estimulação in vitro e in vivo do crescimento e diferenciação das células-tronco neurais (OLIVEIRA; SALINA; ANNUNCIATO, 2001; GUZEN et al., 2008). Ainda não se sabe com clareza se esses fatores são suficientes para a estimulação da recuperação tecidual ou se apenas amplificam essa recuperação quando já iniciada (HORIE et al., 2010).

\section{Uso das células tronco no tratamento de doenças do sistema nervoso}

Atualmente, os vários tipos de células-tronco já descritos estão sendo estudados em modelos animais 
Tabela 1 - Descrição dos fatores neurotróficos, suas funções, locais de ação e meia vida dentro do organismo.

\begin{tabular}{|c|c|c|c|}
\hline Fatores de neurotróficos & Meia vida no organismo & Função & Local de ação \\
\hline $\begin{array}{c}\text { Fator de crescimento do } \\
\text { nervo (NGF) }\end{array}$ & $\begin{array}{c}2-3 \text { horas } \\
30 \text { minutos em Células de } \\
\text { Schwan }\end{array}$ & $\begin{array}{c}\text { Proliferação e diferenciação } \\
\text { de neurônios, crescimento } \\
\text { axonal }\end{array}$ & $\begin{array}{c}\text { Neurônios sensitivos e } \\
\text { motores }\end{array}$ \\
\hline Neurotrofina 3 (NT-3) & $\begin{array}{l}50 \text { minutos em neurônios } \\
\text { do cerebelo }\end{array}$ & $\begin{array}{l}\text { Estimula o crescimento } \\
\text { e diferenciação de novos } \\
\text { neurônios e sinapses }\end{array}$ & $\begin{array}{l}\text { Neurônios do SNC e } \\
\text { também encontrada em } \\
\text { tecido muscular }\end{array}$ \\
\hline Neurotrofina 4 (NT-4) & $\begin{array}{c}\text { Sem dados encontrados na } \\
\text { literatura }\end{array}$ & $\begin{array}{c}\text { Atividade similar à } \\
\text { neurotrofina } 3\end{array}$ & $\begin{array}{c}\text { Neurônios motores e } \\
\text { sensitivos }\end{array}$ \\
\hline $\begin{array}{l}\text { Fator de crescimento } \\
\text { fibroblástico básico (bFGF) }\end{array}$ & $\begin{array}{c}\text { Sem dados encontrados na } \\
\text { literatura }\end{array}$ & $\begin{array}{l}\text { Ajuda na neurogênese, } \\
\text { no crescimento axonal, } \\
\text { na diferenciação e } \\
\text { desenvolvimento e a manter } \\
\text { as células quando adultas }\end{array}$ & $\begin{array}{l}\text { Células-tronco neurais } \\
\text { do hipocampo e da área } \\
\text { subventricular }\end{array}$ \\
\hline $\begin{array}{c}\text { Fator neurotrófico ciliar } \\
\text { (CNTF) }\end{array}$ & 3 minutos & $\begin{array}{c}\text { Diferenciação e auxílio na } \\
\text { sobrevivência neural }\end{array}$ & $\begin{array}{c}\begin{array}{c}\text { Neurônios motores e } \\
\text { sensitivos }\end{array} \\
\end{array}$ \\
\hline $\begin{array}{c}\text { Fator neurotrófico derivado } \\
\text { do cérebro (BNDF) }\end{array}$ & 0,5 a 2,5 horas & $\begin{array}{l}\text { Regeneração e } \\
\text { remielinização }\end{array}$ & $\begin{array}{c}\text { Neurônios do SNP e SNC, } \\
\text { neurônios motores }\end{array}$ \\
\hline $\begin{array}{c}\text { Fator neurotrófico derivado } \\
\text { da glia (GNDF) } \\
\end{array}$ & 3 a 4 dias & $\begin{array}{l}\text { Regeneração e } \\
\text { proteção }\end{array}$ & $\begin{array}{c}\begin{array}{c}\text { Neurônios motores e } \\
\text { sensitivos }\end{array} \\
\end{array}$ \\
\hline $\begin{array}{l}\text { Fator de crescimento } \\
\text { epidérmico (EGF) }\end{array}$ & $\begin{array}{c}\text { Sem dados encontrados na } \\
\text { literatura }\end{array}$ & Diferenciação e proliferação & Células progenitoras \\
\hline
\end{tabular}

Fonte: Oliveira; Salina; Annunciato (2001); Sebben et al. (2011); Guzen et al. (2008); Mudò et al. (2009).

para enfermidades neurológicas, sendo que a maioria dos resultados são bastante otimistas, pois já se demonstraram seguros e, até mesmo, eficazes (OTERO et al., 2009).

As principais estratégias que vem sendo estudadas para aplicação da terapia celular compreendem duas frentes: a possível reposição das células perdidas, caracterizando a regeneração do tecido nervoso; e a indução do processo neurogênico, com regulação e aumento da função das células neurais de forma endógena, por meio da infusão de células-tronco nos sítios danificados (CARRION et al., 2009; OTERO et al., 2009).

As evidências na literatura apontam que a liberação dos fatores tróficos por todas essas células, independente do tipo e origem, induzem essas modificações, além de proteger o tecido contra maiores danos (LIMA; GOMES, 2010). A seguir, estão descritos os tipos celulares que se mostraram mais promissores nos estudos já realizados.

\subsection{Células-tronco embrionárias}

Derivadas da massa interna do blastocisto (PAULA et al., 2005), as células-tronco embrionárias chamam a atenção por serem pluripotentes, ou seja, podem se diferenciar em qualquer célula dos três folhetos embrionários (WALIA et al., 2011) e são consideradas para uso em estudos, somente depois de apresentarem características específicas como: marcadores moleculares específicos e capacidade de divisão celular por várias gerações, constituindo uma população estável (PEREIRA, 2008).

Uma vez injetadas em modelos animais, as células-tronco embrionárias, quando não monitoradas corretamente por meio de técnicas que envolvem a inserção de um marcador fluorescente, podem se dividir descontroladamente e formar teratomas. Por essa razão, diversos protocolos estão sendo elaborados para que se direcione a diferenciação dessas células in vitro para depois serem testadas (PEREIRA, 2008; KRIKS et al., 2011).

Dessa forma, essas células já apresentaram um efeito terapêutico em modelos animais de várias doenças, incluindo Doença de Parkinson (KRIKS et al., 2011), resultados esses que deixam os pesquisadores otimistas e ansiosos para se testar a capacidade das células-tronco embrionárias em seres humanos. Ressalte-se, no entanto, 
que isto evolve questões tanto científicas, como a compatibilidade entre as células e o receptor, quanto éticas, já que testes com células-tronco embrionárias ainda não foram aprovados em alguns países (PEREIRA, 2008; SCHWINDT et al., 2005).

No que diz respeito à compatibilidade, uma estratégia é a realização da clonagem terapêutica, que consiste em se criar um embrião clonado do paciente. A desvantagem dessa técnica é o fato de que, se o problema do paciente for genético, não vale a pena realizar o procedimento já que não irá ajudar (PEREIRA, 2008).

Já os problemas éticos e religiosos atrasam as pesquisas com as células-tronco embrionárias em alguns países como a Itália, o que não ocorre, por exemplo, em países como, Inglaterra, Austrália, Israel, Japão e Estados Unidos, que já estão em estágios avançados de pesquisas com células-tronco embrionárias. Por essa razão, os cientistas têm trabalhado para encontrar alternativas e estas incluem o uso de células-tronco adultas, que não apresentam tais empecilhos e são mais fáceis de manipular que as células-tronco embrionárias (WALIA et al., 2011).

\subsection{Células-tronco da medula óssea}

Dentre todas as células-tronco adultas descritas, as que mais vêm sendo utilizadas são as células originadas da medula óssea, tanto em estudos pré-clínicos como nos clínicos já em decorrência (MENDEZ-OTERO et al., 2007).

As células-tronco da medula óssea são divididas em duas populações distintas: as hematopoiéticas, que são as precursoras das várias linhagens sanguíneas e largamente utilizadas em transplantes de medula para tratamento de doenças como leucemia; e as mesenquimais (SCHWINDT et al., 2005), que são encontradas, em sua maioria, na medula óssea, mas também em outros tecidos do organismo como: pele, tecido adiposo, polpa dentária, placenta e em extremidades encapsuladas dos nervos sensoriais (SCHUSTER et al., 2008; MENDRONE JUNIOR, 2009).

Esta última população de células-tronco se apresenta como uma alternativa para transplantes alogênicos (células provenientes e um doador), pois o fato de apresentarem uma carência de certos receptores coestimulantes, como os antígenos de histocompatibilidade (HLA) da classe II, e também, por secretarem fatores no local que diminuem a resposta das células $\mathrm{T}$, evitam o desencadeamento de processos de rejeição no receptor (SCHUSTER et al., 2008). Por esses motivos, as células-tronco mesenquimais têm se destacado no meio científico.

Além disso, essas células demonstraram em estudos realizados um grande potencial proliferativo e a capacidade de migrarem, integrarem-se e se diferenciarem em células neurais, como neurônios e células da glia, quando infundidas no Sistema Nervoso Central (SNC), além de outros tipos celulares como osteócitos e adipócitos (SCHWINDT et al., 2005; MENDRONE JUNIOR, 2009).

\subsection{Células-tronco neurais}

A descoberta das células-tronco progenitoras neurais abriu um novo leque de possibilidades e ideias, sendo que os primeiros estudos já apresentam resultados promissores (SCHWINDT et al., 2005). O interesse por essas células se dá pelo fato de serem naturalmente neurogênicas, ou seja, capazes de originar os neurônios, as células da astróglia e oligodendróglia, sendo assim, células multipotenciais (PEVNY; NICOLIS, 2009; LIMA; GOMES, 2010).

Um procedimento que vem sendo estudado para se analisar o potencial das células-tronco neurais são as neuroesferas, que são descritas como um conjunto de células, tanto células-tronco progenitoras quanto células-tronco pluripotentes, que possuem a capacidade de se diferenciar nos três tipos celulares do SNC citados anteriormente. São induzidas ao crescimento na presença de fatores de crescimento como FGF-2 (fibroblast growth factor-2) e EGF (epidermal growth factor). Essas neuroesferas apresentam-se ainda em associação com o uso de terapia gênica, pois, após modificações na genética das células que a compõem, é possível que liberem substâncias específicas, que são grandes demais para passar pela barreira hematoencefálica nos locais em que se espera (SCHWINDT et al., 2005).

Além das neuroesferas, a existência de protocolos que permitem o isolamento e multiplicação das células-tronco neurais deu o primeiro passo para que se avaliem formas de se usar essas células com segurança e efetividade. Por esses motivos, a perspectiva dos cientistas é induzir as próprias células-tronco neurais do paciente a se diferenciarem em neurônios específicos ou células da glia, para substituir as que foram perdidas (OTERO et al., 2009; LIMA; GOMES, 2010). 


\subsection{Genes marcadores expresso nas células-tronco neuronais e seu papel na diferenciação celular}

Vários estudos já descreveram a presença e eficiência de marcadores específicos importantes como, por exemplo, Sox2, Oct4, e Nanog, tanto para a diferenciação das células-tronco neurais, quanto para a reprogramação de células somáticas em tais células mencionadas anteriormente (PARK et al., 2007). O gene marcador que mais se destaca é o Sox2, que faz parte da família dos genes Sox (PEVNY; NICOLIS, 2009) juntamente com o Sox 1, o Sox3, o Sox 9 , entre outros.

No que diz respeito ao Sox2, estudos comprovaram que tal gene é ativo no sistema nervoso embrionário desde as primeiras fases de desenvolvimento, principalmente nos precursores indiferenciados. Além disso, a expressão de Sox2 foi detectada nas áreas já descritas como neurogênicas, sendo que, na região do hipocampo, as células que expressam esse gene marcador, comportam-se como células-tronco neurais (PEVNY; NICOLIS, 2009) e também no tecido cerebelar humano e de roedores, juntamente com a expressão do Sox 1 e do Sox 9 , o que indica uma possível existência de células-tronco neurais no cerebelo, ainda que os pesquisadores não entendam onde essas células poderiam se alojar dentro do tecido (ALCOCK et al., 2009).

Notou-se também a expressão de Sox1, Sox 2 e Sox9 nas células da glia de Bergmann, mas ainda não se sabe a exata função desses marcadores, fazendo-se necessária a realização de mais pesquisas (ALCOCK et al., 2009). Em estudos realizados em ratos e rãs do gênero Xenopus, o Sox 2 mostrou-se fundamental para a manutenção da função das células-tronco pluripotentes nos estágios mais precoces da diferenciação, além de depender de fatores de transcrição específicos (PEVNY; NICOLIS, 2009).

Muitos estudos (TAKAHASHI; YAMANAKA, 2006; KIM et al., 2008) têm mostrado o potencial do Sox2 em associação com outros fatores de transcrição como, por exemplo, Oct4, para induzir outros grupos de células a se reprogramarem. Essas células passam por um processo de desdiferenciação, chegando a um estágio em que são chamadas de células-tronco induzidas à pluripotência (iPSCs, na sigla em inglês) para depois serem reprogramadas, por influência de genes como Sox2 e Oct4, a células de diferentes tipos, como as neurais. O gene
Nanog, um marcador de células indiferenciadas, é um dos genes a sofrer a modulação dos genes Sox2 e Oct4, pois a interação deles permite que o Nanog mantenha o estado indiferenciado das células-tronco embrionárias e das células-tronco pluripotente induzidas (PARK et al., 2007; KIM et al., 2008; CROBU et al., 2010; WALIA et al., 2011).

Segundo Park et al. (2008), a expressão ectópica (fora do local esperado) de quatro fatores de transcrição, Oct4, Sox2, Klf4 e Myc, é suficiente para a indução de células adultas à pluripotência, sendo que essas células se assemelham as células-tronco embrionárias. Os pesquisadores demonstraram que somente os genes Oct4 e Sox 2 são essenciais para o processo, enquanto o Klf4 e $M y c$ melhoram a eficiência da formação das colônias. Nesse estudo, os pesquisadores conseguiram com sucesso a reprogramação de fibroblastos adultos, tecido fetal de pulmão e pele, fibroblastos neonatais e células-tronco mesenquimais a um estágio pluripotente. Fato este constatado por Kim et al. (2008), em que os grupos de pesquisadores demonstram por meio de uma técnica de Western Blot, que consiste na separação de proteínas em eletroforese em gel, a expressão desses quatro fatores de transcrição nas amostras dos camundongos estudados; e também por Crobu et al. (2011), em um estudo que mostrou o perfil genético das células-tronco mesenquimais antes e depois do processo de reprogramação, mas, dessa vez, para um destino neuronal.

Outros fatores de transcrição como, por exemplo, Sonic Hedhog (SHh), Pax6 (marcador específico de diferenciação neural), Oct6 (expresso nas células epiblásticas embrionárias e neuroectodérmicas), Otx2 (marcador epiblástico, cuja expressão é mantida durante a diferenciação neural), BMP4 (inibidor de diferenciação neural) e Nocth1, são altamente modulados pelo Sox2 e vice-versa, quando se encontram em superexpressão (PEVNY; NICOLIS, 2009; CHAMBERS et al., 2009; KAMIYA et al. 2011; SUZUKI et al., 2011).

O uso de diferentes combinações desses fatores de transcrição pode dar origem a diferentes tipos de células neurais, como neurônios motores (SON et al., 2011) e dopaminérgicos (CAIAZZO et al., 2011). Dessa forma, a transdiferenciação apresenta-se como uma estratégia promissora nos tratamentos que envolvem uso da terapia celular. 


\section{A terapia celular em doenças neurodegene- rativas}

Cada uma das doenças a seguir, afeta uma população diferente de neurônios, levando à perda de função e, até mesmo, à incapacidade do indivíduo afetado, seja ela apenas motora ou em conjunto com acometimento mental. As doenças são: Acidente Vascular Cerebral, Doença de Parkinson, Esclerose Lateral Amiotrófica, Esclerose Múltipla e Epilepsia. E o que essas doenças apresentam em comum é a ocorrência de processo inflamatório, que pode ser amenizado após administração de células-tronco (HORIE et al., 2010; SON et al., 2011).

A forma de administração dessas células varia, podendo ser por via intravenosa, intra-arterial ou intracerebral, sendo que, quando injetadas, agirão possivelmente na indução do aumento da angiogênese, neurogênese e sinaptogênese, o que resulta no remodelamento do sistema nervoso e melhoramento das funções prejudicadas (CHOPP; LI, 2002).

Dentre todas as doenças que acometem o Sistema Nervoso Central, o Acidente Vascular Cerebral (AVC), também chamado de Acidente Vascular Encefálico (AVE), é a que se destaca. Por ser de ocorrência comum na população, a preocupação com o tratamento desses pacientes é notória, sendo que as terapias existentes visam principalmente auxiliar no aumento da capacidade de regeneração do SNC, para se diminuírem as sequelas deixadas pelo episódio vascular (OTERO et al., 2009).

Atualmente, resultados de diversos estudos realizados com o uso de células-tronco da medula óssea e células-tronco neurais arranjadas em forma de neuroesferas, depois de injetadas em modelos animais, apresentaram efeitos benéficos no que diz respeito à recuperação da função do tecido (HORIE et al., 2010).

No Brasil, dois estudos merecem destaque no uso de células-tronco mononucleares da medula óssea, um deles realizado pela Universidade Federal do Rio de Janeiro, em colaboração com o Hospital Pró-cardíaco (RJ) e outro realizado no Hospital São Lucas, da Universidade Católica do Rio Grande do Sul. O primeiro avaliou sete pacientes isquêmicos que foram monitorados e não apresentaram piora clínica após o transplante das células; notou-se também o aumento do metabolismo cerebral, sendo que todos os pacientes relataram melhora do quadro neurológico. O segundo foi realizado com 20 pa- cientes; destes, 14 não mostraram qualquer complicação relacionada ao procedimento, apontados, portanto, como protocolos seguros. Quanto à eficácia, 70\% dos pacientes apresentaram melhora após três meses de monitoramento (PAULA et al., 2005; MENDONCA et al., 2006).

A Doença de Parkinson é descrita na literatura como uma degeneração progressiva, inicialmente de neurônios dopaminérgicos da região da substância nigra, localizada no mesencéfalo ventral, com deficiência de tirosina hidroxilase; e em estágios mais avançados com perda de neurônios serotonérgicos e noradrenérgicos juntamente com seus respectivos neurotransmissores. É uma doença inicialmente motora, levando à demência. Dentre os diversos mecanismos envolvidos na degeneração neuronal dessa doença, estão incluídas: disfunção mitocondrial, estresse oxidativo, deficiência de fatores neurotróficos e ação do sistema imune (PAULA et al., 2005; PEREIRA et al., 2007).

As pesquisas envolvendo terapia celular na Doença de Parkinson ainda estão em fase precoce. A maioria dos estudos descritos, relacionados com modelos animais, relata a melhora dos sintomas parkinsonianos com transplante de células-tronco embrionárias (PAULA et al., 2005e) e secreção de fatores tróficos como o Fator Neurotrófico Derivado da Glia (GNDF) por neuroesferas, estabelecendo uma neuroproteção (SCHWINDT et al., 2005).

Dentre as estratégias em experimentação, as que se destacam envolvem o uso de células-tronco neurais e/ ou neuroprogenitoras fetais. Tais células já demonstraram em modelos animais a capacidade de influenciar a neurogênese, a angiogênese e a diminuição do processo inflamatório, entre outras vantagens (PEREIRA et al., 2007).

Porém, nos estudos pré-clínicos, os efeitos positivos demonstrados com relação à possível reposição dos neurônios dopaminérgicos, a preservação do circuito neural e a amenização dos sintomas, apresentam questionamentos que precisam ser pesquisados antes que se estabeleça a terapia celular como alternativa para tratamento em pacientes com essa doença (PEREIRA et al., 2007).

Até o momento, a maioria das pesquisas que envolvem terapia celular no tratamento de pacientes tanto com AVC, como portadores de Parkinson, buscou respostas quanto à segurança dos métodos. Isto é, no que diz respeito às formas de administração das células e 
também aos efeitos colaterais que poderiam se apresentar, como rejeição por parte do receptor (OTERO et al., 2009). Quanto à eficácia, muito ainda precisa ser feito e analisado, de forma que não há certeza sobre os efeitos benéficos em humanos, ainda que, em modelos animais, os resultados tenham apresentado dados interessantes.

Em seguida, a Esclerose Lateral Amiotrófica (ELA) se apresenta como uma doença degenerativa dos neurônios motores de caráter progressivo, levando a atrofia, atonia, arreflexia (ausência de reflexos) e fraqueza muscular. Compromete os neurônios motores superiores e inferiores além de, geralmente, envolver a região bulbar e o trato piramidal (NORDON; ESPÓSITO, 2009; LIMA; GOMES, 2010).

Atualmente, há apenas um medicamento aprovado para o tratamento da ELA, o riluzol, que atua na diminuição da lesão acometida pelos neurônios motores. Ressalte-se, no entanto, que a associação com outras substâncias neuroprotetoras e antioxidantes para amenizar os sintomas, fisioterapia e outras atividades multidisciplinares, é comum (LIMA; GOMES, 2010).

Dessa forma, as estratégias com relação ao uso de células-tronco partem de modelos animais, comumente, pela utilização de camundongos SOD1-G93A, que possuem uma mutação na enzima superóxido dismutase1(importante na manutenção do neurônio motor), que gera lesões similares à esclerose lateral amiotrófica em humanos (XU et al., 2009; LIMA; GOMES, 2010).

Nesses camundongos, já foram relatados transplantes de células da medula óssea, células de cordão umbilical, células-tronco neuronais e, até mesmo, células de tecido adiposo. Os dois primeiros tipos aumentaram a expectativa de vida dos animais, sendo que em um dos estudos, os benefícios relatados pelo uso das células da medula foram ditos como devido à mudança no ambiente celular que culminou na geração de células da micróglia e formação de novos neurônios, enquanto as células-tronco neuronais podem se diferenciar em neurônios e colonizar o córtex motor, o hipocampo e a medula espinhal (XU et al., 2009; LIMA; GOMES, 2010), além de poderem se diferenciar em astrócitos, que são deficientes nessa doença e liberar fator neurotrófico de células da glia (GNDF). (KLEIN et al., 2005).

Ainda há relatos na literatura de que a imunossupressão associada ao transplante de células-tronco neuro- nais possibilita uma maior sobrevivência delas no sítio da lesão (YAN et al., 2006). Em humanos, estudos envolvendo células-tronco mesenquimais, relataram desaceleração na diminuição da capacidade linear da força vital e método seguro, apesar de ser difícil monitorar o deslocamento e sobrevida dessas células (LIMA; GOMES, 2010).

Já a Esclerose Múltipla, uma doença autoimune de caráter inflamatório crônico e desmielinizante, leva à degeneração dos axônios com progressiva incapacidade motora. Infelizmente, os tratamentos existentes, baseados na administração de imunossupressores, são apenas parcialmente efetivos, principalmente em fases mais avançadas da doença, sendo estas mais um dos alvos dos cientistas (KARUSSIS et al., 2010; ZHANG et al., 2011).

Ainda que haja relatos na literatura do uso de células-tronco embrionárias e até mesmo de células induzidas à pluripotência em modelos animais, a maioria dos protocolos envolve o uso de células-tronco provenientes da medula óssea (WITHERICK et al., 2010; UCCELI et al., 2011). Muitos estudos demonstraram que o transplante dessas células apresenta ações anti-inflamatórias, imunomoduladoras e propriedades preservativas das funções neurológicas, além de melhorarem a qualidade de vida dos pacientes, diminuindo casos de depressão, muito comuns em indivíduos em fases avançadas da doença (WITHERICK et al., 2010; PASQUINI et al., 2010; GUIMARÃES et al., 2010).

Porém, em se tratando das células-tronco hematopoiéticas autólogas, só são consideradas para uso quando os pacientes se apresentam na fase mais precoce da doença. O uso desse mesmo tipo celular, de origem alogênica, também é levado em consideração, mas ainda não há estudos clínicos específicos para indivíduos com Esclerose Múltipla (PASQUINI et al., 2010).

E, por último, a Epilepsia que se apresenta como um distúrbio cerebral que predispõe o indivíduo a crises epilépticas recorrentes e espontâneas causadas por disparos intensos, sincronizados e rítmicos das células neurais no SNC. As consequências neurobiológicas, cognitivas, fisiológicas e sociais estão entre as variáveis que interferem no bem estar dos pacientes acometidos por essa condição (PAULA et al., 2005; KARUSSIS et al, 2010).

O tratamento atual é realizado com medicamentos antiepilépticos e, ainda assim, não há garantia da diminuição da progressão da doença. Infelizmente, a maioria 
dos pacientes se torna refratário aos medicamentos, ou seja, não responde mais à terapêutica estabelecida. Nesses casos, a realização de cirurgia é a única alternativa curativa, sendo que alguns pacientes ainda precisam tomar os medicamentos (CARRION et al., 2009).

Nos estudos realizados com células-tronco, o modelo animal mais utilizado é o que os animais são tratados com pilocarpina, um agonista colinérgico capaz de mimetizar as manifestações de uma epilepsia de lobo temporal. Nas pesquisas descritas, foram utilizadas células-tronco embrionárias, células-tronco mononucleares e, principalmente, células-tronco neurais em alguns casos, com associação de fatores tróficos, em transplantes no hipocampo dos animais (SHETTY; HATTIAGANDY, 2007; MAISANO et al., 2009; WALDAU et al., 2010).

Os dados obtidos demonstraram que as células transplantadas expressavam marcadores de receptores GABA, marcadores para células da micróglia e neurônios e ainda, propriedades intrínsecas e sinápticas características deles. Além disso, os pesquisadores puderam perceber uma melhora do déficit cognitivo e uma redução das crises recorrentes (CARRION et al., 2009; WALDAU et al., 2010).

Em humanos, o primeiro teste aprovado no Brasil ocorreu em 2007 e teve como objetivo avaliar a segurança e a eficácia do transplante de células-tronco da medula óssea por meio de arteriografia. Os pacientes foram rigorosamente selecionados e, após seis meses de monitoramento, relataram diminuição das crises e aumento da capacidade cognitiva, sem efeitos adversos (CARRION et al., 2009).

\section{Considerações finais}

Desde os transplantes de células da medula óssea, a ideia de se usarem células como terapia para diversas doenças apresenta-se como uma das mais revolucionárias e otimistas que a comunidade científica já se deparou. Esse fato não é diferente quando se trata de pacientes acometidos por doenças incuráveis como as apresentadas neste trabalho.

Como mostrado, várias alternativas envolvendo o uso de células-tronco estão em fase de estudo, tanto em modelos animais quanto em estudos clínicos, visto que os resultados obtidos mostraram-se promissores. Acrescentando-se a essa nova modalidade de terapias as técnicas que envolvem o uso de fatores de transcrição associados com a terapia gênica quebraram a barreira que existia entre os diferentes tecidos embrionários, tornando possível a conversão de um tipo específico celular em outro.

Ainda assim, faz-se necessário um maior entendimento sobre cada tipo de células-tronco em questão, sua melhor forma de administração, melhor forma de extração e expansão in vitro e em qual doença elas melhor se aplicam. Além disso, é preciso manter um melhor controle da diferenciação das células reprogramadas, para que, depois de diferenciadas, elas possam manter as suas características e não desencadear maiores problemas para os pacientes.

É dentro desse cenário que o profissional biomédico, por possuir uma formação acadêmica em biologia molecular, imunologia, genética e biotecnologia, é capaz de assumir pesquisas e estudos clínicos com células-tronco. O conhecimento nessas áreas permite que o biomédico tenha uma melhor visão da estrutura dos cromossomos, das funções dos genes, da relação que um gene tem com outro e dos padrões de herança que influenciam nas características dos indivíduos. Além disso, técnicas como Southern Blot e PCR, muito utilizadas atualmente, possibilitam tanto a manipulação do DNA celular, do DNA mitocondrial, do RNA e, até de proteínas já transcritas, quanto à visualização de suas possíveis mutações. E por fim, faz-se necessário o trabalho em conjunto com outros profissionais da área da saúde como, médicos, farmacêuticos e biólogos, para que se atinja o maior grau de excelência nos resultados que se espera obter.

\section{Referências}

ABREU, S. C. et al. Terapia celular nas doenças respiratórias. Pulmão RJ, Rio de Janeiro, v. 17, n. 2-4, p. 91-97, s.m. 2008.

ALCOCK, J. et al. Expression of Sox1, Sox2 and Sox9 is maintained in adult human cerebellar cortex. Neuroscience Letters, Amsterdam, v. 450, n. 2, p. 114116, jan. 2009. doi: 10.1016/j.neulet.2008.11.047

ALVAREZ-BUYLLA, A.; LIM, D. A. For the long run: maintaining germinal niches in the adult brain. Neuron, United States, v. 41, n. 5, p. 683-686, mar. 2004. doi: $10.1016 / \mathrm{S} 0896-6273(04) 00111-4$

BARTLEY, J. et al. BrdU-positive cells in the neonatal mouse hippocampus following hypoxic-ischemic brain 
injury. BMC Neuroscience, London, v. 6, n. 15, p. 1-9, 2005. doi: 10.1186/1471-2202-6-15

CABELEIRA, A. et al. O sangue do cordão umbilical em medicina regenerativa: uma revisão dos avanços científicos mais recentes. Acta Obstetrícia e Ginecologia Portuguesa, Coimbra, v. 4, n. 2, p. 81-87, jun. 2010.

CAIAZZO, M. et al. Direct generation of functional dopaminergic neurons from mouse and human fibroblasts. Nature, v. 476, n. 7359, p. 224-227, jul. 2011. doi: $10.1038 /$ nature10284

CARRION, M. J. M.; VENTURIN, G. T.; DACOSTA, J. C. Potencial terapêutico das células-tronco da medula óssea no tratamento da epilepsia. Revista Brasileira de Hematologia e Hemoterapia, São Paulo, v. 31, n. 1, p. 112119, maio 2009. doi: 10.1590/S1516-84842009005000023

CHAMBERS, S.M. et al. Highly efficient neural conversion of human ES and iPS cells by dual inhibition of SMAD signaling. Nature Biotechnology, Bethesda, v. 26, n. 3, p. 275-280, mar. 2009. doi: 10.1038/nbt.1529

CHOPP, M.; LI, Y. Treatment of neural injury with marrow stromal cells. The Lancet Neurology, London, v. 1 , n. 2 , p. $92-100$, jun. 2002. doi: 10.1016/S14744422(02)00040-6

GUIMARÃES, F.A.B. et al. Impact of autologous hematopoetic stem cell transplantation on the quality of life of patients with multiple sclerosis. Arquivos de Neuropsiquiatria, São Paulo, v. 68, n. 4, p. 522-527, aug. 2010. doi: 10.1590/S0004-282X2010000400009

GUZEN, F.P. et al. Tratamento farmacológico e regeneração do sistema nervoso central em situações traumáticas. Revista Neurociências, São Paulo, v. 17, n. 2, p. 128-132, abr./jun. 2009.

GUYTON, A.C.; HALL, J.E. Tratado de Fisiologia Médica. 10. ed. Rio de Janeiro: Elsevier, 2002.

HORIE, N. et al. Transplanted stem cell-secreted VEGF effects post-stroke recovery, inflammation, and vascular repair. Stem Cells, Basel, v. 29, n. 2, p. 274-285, feb. 2011. doi: $10.1002 /$ stem. 584

MENDRONE JUNIOR, A. Sangue periférico como fonte de células para terapia celular. Revista Brasileira de Hematologia e Hemoterapia, São Paulo, v. 31, supl. 1, p. 19-24, maio 2009. doi: 10.1590/S151684842009005000026

JIM, W., XING, Y., YANG, A. Epidermal growth factor promotes the differentiation of stem cells derived from human umbilical cord blood into neuron-like cells via taurine induction in vitro, in vitro cellular and developmental biology. In Vitro Cellular \& Development Biology - Animal, Berlin, v. 45, n. 7, p. 321-327, aug. 2009. Doi: $10.1007 / \mathrm{s} 11626-009-9184-7$

KAMIYA, D. et al. Intrinsic transition of embryonic Stem-cell differentiation into neural Progenitors. Nature, London, v. 470, n. 4335, p. 503-510, feb. 2011. doi: 10.1038/nature09726

KARUSSIS, D. et al. Safety and immunological effects of mesenchymal stem cell transplantation in patients with multiple sclerosis and amyotrophic lateral sclerosis. Archives of Neurology, Chicago, v. 67, n. 10, p. 1187 1194, oct. 2010. doi: 10.1001/archneurol.2010.248

KIERNAN, J. A. Neuroanatomia Humana de Barr. 7. ed. Barueri, SP: Manole, 2003.

KIM, J. B. et al. Pluripotent stem cells induced from adult neural stem cells by reprogramming with two factors. Nature, London, v. 454, n. 7204, p. 646-651, jul. 2008. doi: 10.1038 /nature07061

KLEIN, S. M. et al. GDNF delivery using human neural progenitor cells in a rat model of ALS. Human Gene Theraphy, New York, v. 16, n. 4, p. 509-521, apr. 2005. doi: 10.1089/hum.2005.16.509

KRIKS, S. et al. Dopamine neurons derived from human ES cells efficiently engraft in animal models of Parkinson's disease. Nature, London, v. 480, n. 7378, p. 547-551, nov. 2011. doi: $10.1038 /$ nature 10648

LIMA, R. S.; SOARES, M. P. B.; SANTOS, R. R. Terapia celular na doença de Chagas. Revista Brasileira de Hematologia e Hemoterapia, São Paulo, v. 31, n. 1, p. 8789, maio 2009. doi: 10.1590/S1516-84842009005000037

LIMA, S. R.; GOMES, K. B. Esclerose lateral amiotrófica e o tratamento com células-tronco. Revista Brasileira de Clínica Médica, São Paulo, v. 8, n. 6, p. 531-537, nov./ dez. 2010.

MENDEZ-OTERO, R. et al. Potential roles of bone marrow stem cells in stroke therapy. Regenerative Medicine, London, v. 2, n. 4, p. 417-423, jul. 2007. doi: 10.2217/17460751.2.4.417

MENDONÇA, M.L.etal.Safetyofintra-arterialautologous bone marrow mononuclear cell transplantation for acute ischemic stroke. Arquivos Brasileiros de Cardiologia, São Paulo, v. 86, n. 1, p. 52- 55, jan. 2006. doi: 10.1590/ S0066-782X2006000100008

MUDO, G. et al. The FGF-2/FGFRs neurotrophic system promotes neurogenesis in the adult brain. Journal of Neural Transmission, Wien, v. 116, n. 8, p. 995-1005, aug. 2009. doi: 10.1007/s00702-009-0207-z 
NISSHIKAWA, S. I.; GOLDSTEIN, R. A.; NIERRAS, C. $\mathrm{R}$. The promise of human induced pluripotent stem cells for research and therapy. Nature Reviews Molecular Cell Biology, London, v. 9, n. 9, p. 725-729, sep. 2009. doi: $10.1038 / \mathrm{nrm} 2466$

NORDON, D.G.; ESPÓSITO, S.B. Atualização em esclerose lateral amiotrófica. Revista da Faculdade de Ciências Médicas de Sorocaba, Sorocaba, v. 11, n. 2, p. 1-3, abr./jun. 2009.

OLIVEIRA, C. E. M.; SALINA, M. E.; ANNUNCIATO, N. F. Fatores ambientais que influenciam a plasticidade do SNC. Acta Fisiátrica, São Paulo, v. 8, n. 1, p. 6-13, jan. 2001.

OTERO, R. M. et al. Terapia celular no acidente vascular cerebral. Revista Brasileira de Hematologia e Hemoterapia, São Paulo, v. 31, Supl. 1, p. 99-103, maio 2009. doi: 10.1590/S1516-84842009005000030

PASQUINI, M. C. et al. Hematopoietic stem cell transplantation for multiple sclerosis: collaboration of the CIBMTR and EBMT to facilitate international clinical studies. Biology Blood Marrow Transplant, Charlottesville, v. 16, n. 8, p. 1076-1083, aug. 2010. doi: 10.1016/j.bbmt.2010.03.012

PARK, I. H. et al. Reprogramming of human somatic cells to pluripotency with defined factors. Nature, London, v. 451, n. 7175 , p. $141-147$, dec. 2007. doi: 10.1038/ nature 06534

PAULA, S. et al. O potencial terapêutico das célulastronco em doenças do sistema nervoso. Scientia Medica, Porto Alegre, v. 15, n. 4, p. 263-269, out./dez. 2005.

PEREIRA, L. V. A importância do uso de células-tronco para a saúde pública. Ciência \& Saúde Coletiva, Rio de Janeiro, v. 13, n. 1, p. 7-14, jan./fev. 2008. doi: 10.1590/ S1413-81232008000100002

PEREIRA, M.C.L. etal. Estratégias para neurorrestauração em modelos experimentais de doença de Parkinson. Einstein, São Paulo, v. 5, n. 4, p. 387-391, out./dez. 2007.

PEVNY, L. H.; NICOLIS, S. K. Sox2 roles in neural stem cells. The International Journal of Biochemistry \& Cell Biology, Amsterdam, v. 42, n. 3, p. 421-424, mar. 2009. doi: 10.1016/j.biocel.2009.08.018

SCHUSTER, M. D.; MARTENS, T. P.; ITESCU, S. Células-tronco mesenquimais para reparo cardíaco. Revista Brasileira de Cardiologia Invasiva, São Paulo, v. 16, n. 1, p. 95-101, jan./mar. 2008. doi: 10.1590/S217983972008000100018 células-tronco. Jornal Brasileiro de Neurocirurgia, São Paulo, v. 16, n. 1, p. 13-19, jan. 2005.

SEBBEN, A. D. et al. Efeitos de fatores neurotróficos sobre o reparo de nervo periférico. Scientia Medica, Porto Alegre, v. 21, n. 2, p. 81-89, abr./jun. 2011.

SON, E. Y. et al., Conversion of mouse and human fibroblasts into functional spinal motor neurons. Cell Stem Cell, United States, v. 9, n. 3, p. 205-218, sep. 2011. doi: 10.1016/j.stem.2011.07.014

SOUZA, M. L. S.; ELIAS, D. O. Células-tronco e seu potencial na reparação de órgãos e tecidos. Manual de Instrução Programada: princípios de Hematologia e Hemoterapia, v. 2, p. 1-13, 2005. Disponível em: <http:// perfline.com/cear/artigos/stem.pdf $>$ Acesso em: 11 abr. 2013.

SOUZA, V. F. et al. Células-tronco uma breve revisão. Revista de Ciências Médicas e Biológicas, Salvador, v. 2, n. 2, p. 251-256, maio/ago. 2003.

SUZUKI et al. Analysis of altered gene expression specific to embryotoxic chemical treatment during embryonic stem cell differentiation into myocardiac and neural cells. The Journal of Toxicological Sciences, Sendai, v. 36, n. 5, p. 569-585, oct. 2011. doi: 10.2131/jts.36.569

TAKAHASHI, K.; YAMANAKA, S. Induction of pluripotent stem cells from mouse embryonic and adult fibroblast cultures by defined factors. Cell, United States, v. 126, n. 4, p. 663-676, aug. 2006. doi: 10.1016/j. cell.2006.07.024

UCCELLI, A.; LARONI, A.; FREEDMAN, M. S. Mesenchymal stem cells for the treatment of multiple sclerosis and other neurological diseases. The Lancet Neurology, London, v. 10, n. 7, p. 649-56, jul. 2011. doi: 10.1016/S1474-4422(11)70121-1

WALIA, B. et al. Induced pluripotent stem cells: fundamentals and applications of the reprogramming process and its ramifications on regenerative medicine. Stem Cell Reviews and Reports, United States, v. 8, n. 1, p. 100-115, mar. 2011. doi: 10.1007/s12015-0119279-x

WITHERICK, J. et al. Mechanisms of oxidative damage in multiple sclerosis and a cell therapy approach to treatment. Autoimmune Diseases, v. 2011, p. 1-11, dec. 2011. doi: $10.4061 / 2011 / 164608$

XU, L. et al. Human neural stem cell grafts in the spinal cord of SOD1 transgenic rats: differentiation and structural integration into the segmental motor circuitry. The Journal of Comparative Neurology, v. 514, n. 4, p. 297-309, jun. 2009. doi: 10.1002/cne.22022 
YAN, et al. Combined immunosuppressive agents or CD4 antibodies prolong survival of human neural stem cell grafts and improve disease outcomes in amyotrophic lateral sclerosis transgenic mice. Stem Cells, Basel, v. 28, n. 8, p. 1976-1985, aug. 2006. doi: 10.1634/ stemcells.2005-0518

YARAK, S.; OKAMOTO, O. K. Células-tronco derivadas de tecido adiposo humano: desafios atuais e perspectivas clínicas. Anais Brasileiros de Dermatologia, Rio de Janeiro, v. 85, n. 5, p. 647-656, set./out. 2010. doi: 10.1590/ S0365-05962010000500008

ZHANG, H. et al. Central nervous system remyelination in culture: a tool for multiple sclerosis research. Experimental Neurology, Oxford, v. 230, n. 1-2, p. 138148, jul. 2011. doi: 10.1016/j.expneurol.2011.04.009 
Para publicar na revista Universitas:

Ciências da Saúde, acesse o endereço eletrônico www.publicacoesacademicas.uniceub.br.

Observe as normas de publicação, para facilitar e agilizar o trabalho de edição. 